\title{
Determination of imidocarb in animal biosamples using simple high-performance liquid chromatography with diode-array detection
}

\author{
JIN-A. PARK, HEE-JUNG CHO, SOO-MIN CHO, NA-HYUN KIM, DONG-SOON KIM, \\ DAN ZHANG, SEONG-KWAN KIM, HEE YI and HO-CHUL SHIN \\ Department of Veterinary Pharmacology and Toxicology, College of Veterinary Medicine, \\ Konkuk University, Seoul 143-701, Republic of Korea
}

Received October 01, 2013; Accepted October 21, 2013

DOI: $10.3892 /$ br.2013.189

\begin{abstract}
The aim of this study was to develop an analytical method for detection of imidocarb [1,3-bis[3-(4,5-dihydro-1h-imidazol-2-yl)phenyl]urea] in beef and milk using high-performance liquid chromatography (HPLC) with diode-array detection (DAD). Imidocarb was separated on a reversed-phase column $(4.6 \times 250 \mathrm{~mm}, 5 \mu \mathrm{m})$ with a mobile phase consisting of $85: 15(\mathrm{v} / \mathrm{v})$ 0.1\% trifluoroacetic acid/acetonitrile. The flow rate was $1 \mathrm{ml} / \mathrm{min}$, and the column temperature was maintained at $20^{\circ} \mathrm{C}$. Detection was carried out at $260 \mathrm{~nm}$ using a DAD detector. The analytical samples were extracted using a solid-phase extraction (SPE) method. The calibration curves showed good linearity $(r \geq 0.998)$. Limits of quantifications (LOQs) were $0.15 \mathrm{mg} / \mathrm{kg}$ in beef and $0.025 \mathrm{mg} / \mathrm{kg}$ in milk. Intra- and inter-day precisions were 3.2-6.1 and 1.4-6.9\%, respectively, and the accuracy (recovery) was 80.4-82.2\% and $80.1-89.5 \%$ in beef and milk, respectively. Thus, an analytical protocol using SPE extraction followed by HPLC with DAD was successfully developed, which demonstrated acceptable precision and recovery.
\end{abstract}

\section{Introduction}

Imidocarb [1,3-bis[3-(4,5-dihydro-1h-imidazol-2-yl)phenyl] urea] is a carbanilide derivative and chemotherapeutic, chemoprophylactic agent with antiprotozoal activity. Imidocarb is usually administered as dipropionate salt (1-3). In veterinary medicine, it is used in cattle, horses, sheep, and domestic animals including cats and dogs, for the treatment of anaplasmosis and

Correspondence to: Professor Ho-Chul Shin, Department of Veterinary Pharmacology and Toxicology, College of Veterinary Medicine, Konkuk University, Hwayang-dong, Kwangjin-gu, Seoul 143-701, Republic of Korea

E-mail: hshin@konkuk.ac.kr

Key words: imidocarb, residue analysis, milk, beef, high-performance liquid chromatography babesiosis (4-8). Findings of recent studies show that significant residues of imidocarb were detected in bovine and ovine tissues and milk following the administration of ${ }^{14} \mathrm{C}$-imidocarb dipropionate $(2,3,9)$. For this reason, maximum residue limits (MRL) of imidocarb have been set by CODEX, Europe, Middle East and Africa and other countries, including Japan and Korea. The MRLs imposed by the Korea Food and Drug Administration (KFDA) are $0.3 \mathrm{mg} / \mathrm{kg}$ for bovine muscle, $1.5 \mathrm{mg} / \mathrm{kg}$ for bovine liver, $0.05 \mathrm{mg} / \mathrm{kg}$ for bovine fat, $2 \mathrm{mg} / \mathrm{kg}$ for bovine kidney and $0.05 \mathrm{mg} / \mathrm{kg}$ for bovine milk (10).

Recently, Ishii et al (5) and Inoue et al (6) reported a liquid chromatographic method with detection by tandem mass spectrometry (LC-MS/MS) for monitoring imidocarb in bovine tissue and milk. However, simple analytical methods, such as high-performance liquid chromatography (HPLC), for monitoring imidocarb residues in various animal tissues are not well developed. In general, if it provides satisfactory sensitivities for determination levels of residues less than their MRLs, HPLC is preferred over LC-MS/MS due to cost benefits and ease of handling. Therefore, we have developed an HPLC method to quantify imidocarb residues in animal tissues using a solid-phase extraction (SPE) clean-up process. Wang et al (8) suggested an HPLC method for imidocarb residue determination in swine tissue, however, this method did not involve a solid-phase clean-up process. Tarbin and Shearer (11) also reported a method for determining imidocarb using HPLC with SPE, however, that method was applied only to a bovine kidney sample. Thus, the aim of the present study was to develop a sensitive and economic method for imidocarb detection in beef and milk samples using HPLC with DAD.

\section{Materials and methods}

Chemical and reagents. Imidocarb, trifluoroacetic acid, ammonium hydroxide $\left(\mathrm{NH}_{3}\right.$ content $\left.20.8-30.0 \%\right)$ and acetic acid were purchased from Sigma-Aldrich (St. Louis, MO, USA). Acetonitrile, methanol and hexane HPLC-grade solvents were provided by JT Baker (Phillipsburg, NJ, USA). Sodium sulfate was purchased from Junsei Chemical (Tokyo, Japan). Any other chemicals and solvents were of analytical grade. Oasis weak cation exchange (WCX) $(60 \mathrm{mg} / 3 \mathrm{ml})$ 
Table I. The accepted criteria for the analytical method.

\begin{tabular}{|c|c|c|c|c|}
\hline \multicolumn{2}{|c|}{ Recovery } & \multicolumn{3}{|c|}{ Relative standard deviation (\%) } \\
\hline $\begin{array}{l}\text { Concentration } \\
(\mu \mathrm{g} / \mathrm{kg})\end{array}$ & $\begin{array}{c}\text { Acceptable recovery, } \\
\text { range }(\%)\end{array}$ & $\begin{array}{l}\text { Concentration } \\
(\mu \mathrm{g} / \mathrm{kg})\end{array}$ & $\begin{array}{c}\text { Within laboratory } \\
(\%)\end{array}$ & $\begin{array}{c}\text { Between laboratories } \\
(\%)\end{array}$ \\
\hline$\leq 1$ & $50-120$ & $\leq 1$ & 35 & 53 \\
\hline$>1, \leq 10$ & $60-120$ & $>1, \leq 10$ & 30 & 45 \\
\hline$>10, \leq 100$ & $70-110$ & $>10, \leq 100$ & 20 & 32 \\
\hline$\leq 100, \leq 1,000$ & $70-110$ & $\leq 100, \leq 1,000$ & 15 & 23 \\
\hline$\leq 1,000$ & $70-110$ & $\leq 1,000$ & 10 & 16 \\
\hline
\end{tabular}

Calibration, 6 points (maximum residue limits of $0.5,1,2,3,4$ and 5 times), $R^{2} \geq 0.95, R \geq 0.99$.

was obtained from Waters Corporation (Milford, MA, USA). Buffer solutions prepared for HPLC were filtered through a $0.45-\mu \mathrm{m}$ GHP membrane filter (Pall, Ann Arbor, MI, USA). Animal extract samples were filtered through a $0.45-\mu \mathrm{m}$ GHP syringe filter (Pall). Beef and commercial whole milk were purchased from large markets. Preliminary analysis indicated that the samples were analyte-free.

Standard solutions. Stock solutions of $1,000 \mu \mathrm{g} / \mathrm{ml}$ imidocarb were prepared in water and stored at $-4^{\circ} \mathrm{C}$. The working solutions for HPLC injections were prepared daily from stock solution mixtures of $0.1 \%$ trifluoroacetic acid in water and acetonitrile $(85: 15, \mathrm{v} / \mathrm{v})$.

Sample preparation. Beef $(5 \mathrm{~g})$ and milk $\left(5 \mathrm{ml}+5 \mathrm{~g}\right.$ of $\left.\mathrm{Na}_{2} \mathrm{SO}_{4}\right)$ samples were transferred to $50-\mathrm{ml}$ conical tubes. Acetonitril e:methanol:trifluoroacetic acid $(10 \mathrm{ml}, 495: 500: 5, \mathrm{v} / \mathrm{v} / \mathrm{v})$ was added and the resulting solution was vortex-mixed for $10 \mathrm{~min}$ and centrifuged at 3,500 $\mathrm{x}$ g for $20 \mathrm{~min}$. The supernatant was gently transferred to $15-\mathrm{ml}$ conical tubes and re-extracted with $5 \mathrm{ml}$ of acetonitrile:methanol:trifluoroacetic acid (495:500:5, $\mathrm{v} / \mathrm{v} / \mathrm{v})$, vortex-mixed for $10 \mathrm{~min}$ and centrifuged at 3,500 $\mathrm{x}$ g for $20 \mathrm{~min}$. The first and second extracts were combined and the resulting solution was evaporated to dryness under nitrogen at $50^{\circ} \mathrm{C}$. The resulting evaporation residue was dissolved in $2 \mathrm{ml}$ of water and $0.5 \mathrm{ml}$ of hexane, after which the solution was vortex-mixed for $1 \mathrm{~min}$. The samples were then added to a Waters Oasis ${ }^{\mathrm{TM}}$ WCX cartridge $(60 \mathrm{mg})$ after the cartridge was conditioned with $3 \mathrm{ml}$ of methanol and equilibrated with $3 \mathrm{ml}$ of water. The loaded cartridge was washed with $3 \mathrm{ml}$ of methanol and $2 \%$ ammonium hydroxide. The analyte was eluted with $3 \mathrm{ml}$ of acetonitrile:methanol:trifluoroacetic acid $(50: 45: 5, \mathrm{v} / \mathrm{v} / \mathrm{v})$ followed by evaporation under a nitrogen stream at $50^{\circ} \mathrm{C}$. The concentrated residues were then dissolved in $5 \mathrm{ml}$ (beef sample) and $1 \mathrm{ml}$ (milk sample) of mobile phase [0.1\% trifluoroacetic acid in water and acetonitrile $(85: 15, \mathrm{v} / \mathrm{v})]$ and filtered through a $0.45-\mu \mathrm{m}$ GHP syringe filter.

Chromatographic quantification. Imidocarb residue levels were quantified via HPLC using an Agilent series 1100 instrument (Palo Alto, CA, USA). The HPLC columns were equipped with a quart pump (G1311A), degasser (G1322A), autosampler (G1313A), column oven (G1316A) and diode-array detection

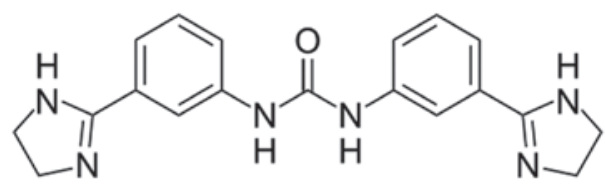

Figure 1. Structure of imidocarb.

(DAD) detector (G1315B). The samples $(20 \mu \mathrm{l})$ were separated on a $\mathrm{C}_{18}$ column (Waters Xbridge, 4.6x250 mm, particle size: $5 \mu \mathrm{m}$; Waters) maintained at $20^{\circ} \mathrm{C}$. The mobile phase consisted of $0.1 \%$ trifluoroacetic acid in water and acetonitrile (85:15, $\mathrm{v} / \mathrm{v})$. The flow rate was fixed at $1.0 \mathrm{ml} / \mathrm{min}$ and the DAD detector was set at $260 \mathrm{~nm}$.

Method validation. The method developed was validated to ensure the criteria specified by the CODEX guidelines for specificity, linearity, limits of detection (LOD) and quantification (LOQ), accuracy and precision (12). Blank samples (beef muscle and commercial milk) were assessed for matrix interferences. Linearity was evaluated for each of the investigated samples (beef muscle and commercial milk) using samples spiked with six concentration levels $[0.5,1,2,3,4$ and 5 times the permitted limit (MRL)]. Each sample was analyzed four times. Calibration curves were calculated via least-squares linear regression analysis of the peak area ratio of each analyte.

The LOD calculations were based on the standard deviation of the y-intercepts $(\sigma)$ and the slope (S) determined by regression analyses, using the equation $\mathrm{LOD}=3.3 \mathrm{\sigma} / \mathrm{S}$. The $\mathrm{LOQ}$ was calculated using the equation $\mathrm{LOQ}=10 \sigma / \mathrm{S}(13)$.

Recoveries were obtained for fortified samples at concentrations of $0.5,1$ and 2 times their MRLs. Five samples were prepared for each concentration level. The responses obtained when imidocarb was added to blank samples prior to extraction were compared with those in which imidocarb was added after extraction. In the inter-laboratory investigations, recoveries and precisions were assessed using fortified samples at MRL concentrations (1 time). Five samples were prepared for each concentration level. Method precision was expressed as the relative standard deviation (RSD). The accepted criteria for the analytical method are shown in Table I. 
Table II. Linearity parameters of imidocarb in spiked beef and milk.

\begin{tabular}{lccccc}
\hline Sample & $\begin{array}{c}\text { Range } \\
(\mathrm{mg} / \mathrm{kg})\end{array}$ & Slope & Intercept & $\mathrm{R}$ & $\begin{array}{c}\text { LOD } \\
(\mathrm{mg} / \mathrm{kg})\end{array}$ \\
\hline Beef & $0.15-1.5$ & $40.814 \pm 0.773$ & $-0.180 \pm 0.353$ & $0.998 \pm 0.002$ & 0.05 \\
Milk & $0.025-0.25$ & $235.668 \pm 16.651$ & $0.178 \pm 0.996$ & $0.998 \pm 0.002$ & 0.008 \\
\hline
\end{tabular}

LOQ, limits of quantification. R, coefficient of correlation.

Table III. Precision and accuracy (recovery) of imidocarb in spiked beef and milk.

\begin{tabular}{|c|c|c|c|c|c|}
\hline \multirow[b]{2}{*}{ Sample } & \multirow[b]{2}{*}{$\begin{array}{c}\text { Concentration } \\
(\mathrm{mg} / \mathrm{kg})\end{array}$} & \multicolumn{2}{|c|}{ Intra-day $(n=3)$} & \multicolumn{2}{|c|}{ Inter-day $(\mathrm{n}=5)$} \\
\hline & & $\begin{array}{l}\text { Precision } \\
\text { RSD (\%) }\end{array}$ & $\begin{array}{c}\text { Accuracy } \\
\text { recovery }(\%)\end{array}$ & $\begin{array}{l}\text { Precision } \\
\text { RSD (\%) }\end{array}$ & $\begin{array}{c}\text { Accuracy } \\
\text { recovery }(\%)\end{array}$ \\
\hline \multirow[t]{3}{*}{ Beef } & 0.15 & 3.2 & 81.2 & 4.8 & 81.4 \\
\hline & 0.3 & 3.2 & 80.2 & 1.4 & 80.4 \\
\hline & 0.6 & 4.0 & 81.5 & 2.8 & 82.2 \\
\hline \multirow[t]{3}{*}{ Milk } & 0.025 & 3.9 & 80.7 & 3.4 & 87.8 \\
\hline & 0.05 & 6.1 & 83.3 & 6.8 & 88.3 \\
\hline & 0.1 & 5.8 & 80.1 & 6.9 & 89.5 \\
\hline
\end{tabular}

RSD, relative standard deviation.

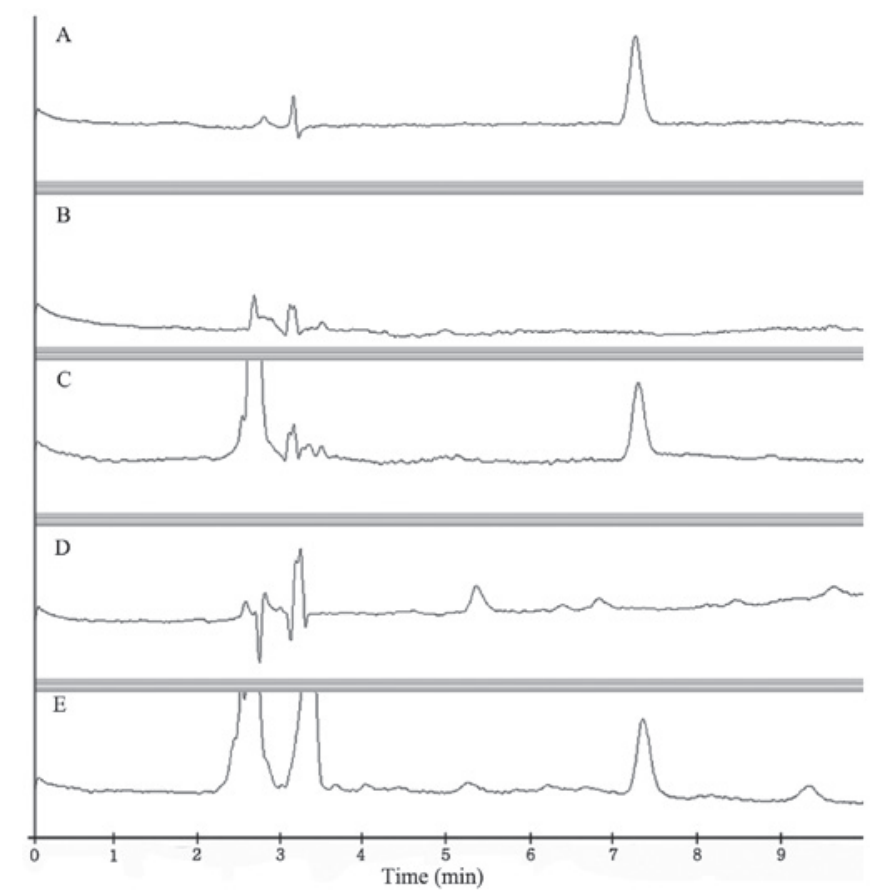

Figure 2. High-performance liquid chromatography chromatograms of (A) imidocarb standards, (B) blank beef sample, (C) beef sample spiked with imidocarb, (D) blank milk sample and (E) milk sample spiked with imidocarb.

\section{Results and Discussion}

An HPLC analysis method was developed to detect imidocarb residues in beef and milk. The imidocarb chemical structure
Table IV. Recovery of imidocarb in beef and milk (inter laboratories) at $1 \mathrm{mg} / \mathrm{kg}$.

\begin{tabular}{lccc}
\hline & & \multicolumn{2}{c}{ Recovery $(\mathrm{n}=5)$} \\
\cline { 3 - 4 } Laboratory & Sample & RSD (\%) & Mean (\%) \\
\hline Lab 1 & Beef & 4.0 & 84.2 \\
& Milk & 4.1 & 90.5 \\
Lab 2 & Beef & 1.3 & 96.0 \\
& Milk & 6.0 & 87.2 \\
\hline
\end{tabular}

RSD, relative standard deviation.

is shown in Fig. 1. The appropriate mobile-phase conditions were established by varying the ratio of $0.1 \%$ trifluoroacetic acid solution and acetonitrile. The effect of the organic solvent on imidocarb retention was investigated by varying the acetonitrile ratios in the mobile phase; $11,12,15$ and $20 \%$ acetonitrile ration resulted in imidocarb retention times of $\sim 17$, 12.5, 7.4 and $3.5 \mathrm{~min}$, respectively. The linear isocratic mobile phase [consisting of $0.1 \%$ trifluoroacetic acid in water and acetonitrile $(85: 15, \mathrm{v} / \mathrm{v})]$ showed optimal separation given the intensities of the analyte peaks, where the imidocarb retention time was $7.4 \mathrm{~min}$.

To extract imidocarb from the samples, a mixture of acetonitrile and methanol was used. The recovery of imidocarb was $<30 \%$ by acetonitrile extraction. Optimal recovery was obtained utilizing a mixture of acetonitrile:methanol:trifluoro 
acetic acid (495:500:5, v/v/v). The average recovery was $>80 \%$ and, therefore, highly satisfactory. A SPE clean-up using a WCX cartridge was performed following extractions of the acetonitrile:methanol:trifluoroacetic acid (495:500:5, v/v/v). No difference was observed between SPE and non-SPE in terms of recovery. However, the interference peak was not observed in either the beef or milk sample after clean-up with SPE using a WCX cartridge. Thus, highly satisfactory chromatograms and recoveries were obtained using these procedures.

The specificity of the method for each sample was evaluated by analyzing blank samples. None of these samples exhibited interferences from beef and milk. As shown in Fig. 2, imidocarb was extracted successfully from beef and milk.

The chromatographic method demonstrated linearity at six concentration levels $(0.5,1,2,3,4$ and 5 times the permitted MRL) ( $n=4, r \geq 0.99)$. The calibration data, as well as the LOD and LOQ, are provided in Table II. The LOQ were $0.15 \mathrm{mg} / \mathrm{kg}$ for beef and $0.025 \mathrm{mg} / \mathrm{kg}$ for commercial milk, respectively. The LOQs in the matrices examined were lower than the MRL imposed by the KFDA for these compounds (10).

The precision and accuracy (recovery) of the method were determined using intra-day $(n=3)$ and inter-day $(n=5)$ methods and three different concentrations. The results are shown in Table III. Matrices were analyzed at concentrations of 0.5 , 1 and 2 times the limits permitted in accordance with the CODEX guidelines. The RSD values (\%) were 3.2-6.1 and 1.4-6.9 for the intra-day and inter-day precisions, respectively. The accuracies of imidocarb in the spiked samples were $80.4-82.2 \%$ in beef muscle and $80.1-89.5 \%$ in milk.

The accuracy and precision of the method in the inter-laboratory context were expressed as a recovery value [mean $(\%)$, RSD (\%)]. Matrices were analyzed at concentrations of 1 time the permitted MRLs. The mean recovery rates of imidocarb were $80.5-91.9 \%$ in the spiked beef samples and $86.9-94.3 \%$ in the spiked milk samples (Table IV).

The proposed methods were applied to determine the possible foundation of imidocarb in 10 different beef and milk samples purchased from large markets in Seoul. Imidocarb was not detected in any of the samples.

In conclusion, the HPLC analytical method described in the present study has been applied successfully to separate and detect imidocarb residues. The developed method has also demonstrated acceptable precision and accuracy (recovery).
The procedure is simple and allows for high-sensitivity determination of imidocarb residues in beef and milk.

\section{Acknowledgements}

This study was supported by KFDA (11162-002) in 2012.

\section{References}

1. Ayoob AL, Hackner SG and Prittie J: Clinical management of canine babesiosis. J Vet Emerg Crit Care (San Antonio) 20: 77-89, 2010.

2. EMEA: The European Agency for the Evaluation of Medicinal Products, Veterinary Medicines and Information Technology. Imidocarb (Extension to sheep): Summary report (3) - Committee for Veterinary Medicinal Products.EMEA/MRL/881/03-FINAL www.ema.europa.eu..

3. Su D, Li XB, Wang ZJ, Wang L, Wu WX and Xu JQ: Pharmacokinetics and bioavailability of imidocarb dipropionate in swine. J Vet Pharmacol Ther 30: 366-370, 2007.

4. Adaszek L, Winiarczyk S, Lukaszewska J and Heile C: Feline babesiosis. Kleintierpraxis 55: 624-628, 2010.

5. Ishii R, Takahashi K and Matsumoto R: Analysis of imidocarb in livestock and seafood products using LC-MS/MS. Shokuhin Eiseigaku Zasshi 52: 34-39, 2011.

6. Inoue K, Nunome M, Hino T and Oka H: Determination of Imidocarb in bovine tissues and milk samples by LC-MS/MS. J Liq Chromatogr Relat Technol 34: 2149-2156, 2011.

7. Rashid A, Mubarak A and Hussain A: Babesiosis in equines in Pakistan: a clinical report. Vet Ital 45: 391-395, 2009.

8. Wang Z, Li X, Su D, Li Y, Wu L, Wang Y and Wu W: Residue depletion of imidocarb in swine tissue. J Agric Food Chem 57: 2324-2328, 2009.

9. Lewis KM, Cohn LA, Birkenheuer AJ and Papich MG: Pharmacokinetics of diminazene diaceturate in healthy cats. J Vet Pharmacol Ther 35: 608-610, 2012.

10. Ministry of Food and Drug Safety. Republic of Korea. Korean Food Standards Codex, appendix 7 MRLs for veterinary drugs in foods: 2013-204. www.mfds.go.kr.

11. Tarbin JA and Shearer G: High-performance liquid chromatographic determination of imidocarb in cattle kidney with cation-exchange clean-up. J Chromatogr 577: 376-381, 1992.

12. Codex Alimentarius: Guidelines for the design and implementation of national regulatory food safey assurance programme associated with the use of veterinary drugs in food producing animals: CAC/GL 71-209. http://www.codexalimentarius.org/ standards/list-of-standards/en.

13. Christodoulou EA, Samanidou VF and Papadoyannis IN: Validation of an HPLC-UV method according to the European Union Decision 2002/657/EC for the simultaneous determination of 10 quinolones in chicken muscle and egg yolk. J Chromatogr B Analyt Technol Biomed Life Sci 859: 246-255, 2007. 